\title{
Physical Effectiveness of Safety Interventions in Fire Engines to Reduce Potential Airborne Transmission of SARS-CoV-2 (COFIRE)
}

\author{
Elmar Bourdon ${ }^{1,}{ }^{*}$, Thomas Schaefer ${ }^{2}$, Maximilian Kittel ${ }^{3}$, Matthias Raedle ${ }^{4}$ and Alexandra Heininger ${ }^{5}$
}

1 PhD in Public Health, Research Associate, Institute of Medical Technology, Heidelberg University and Mannheim University of Applied Sciences, Theodor-Kutzer-Ufer 1-3, D-68167 Mannheim, Germany; elmar.bourdon@medtech.uni-heidelberg.de and Fire Chief, Community Fire Department, Muehlenweg 5-7, D-68549 Ilvesheim, Germany

$2 \mathrm{PhD}$ in Engineering, Senior Scientist, Center for Mass Spectrometry and Optical Spectroscopy (CeMOS), Mannheim University of Applied Sciences, Paul-Wittsack-Str. 10, D-68163 Mannheim, Germany; t.schaefer@hs-mannheim.de

3 MD, Department of Clinical Chemistry, University Medical Center Mannheim, Medical Faculty Mannheim of Heidelberg University, Theodor-Kutzer-Ufer 1-3, D-68167 Mannheim, Germany; maximilian.kittel@umm.de

$4 \mathrm{PhD}$ in Physics, Professor for Physics and Instrumentation, Deputy Head, Center for Mass Spectrometry and Optical Spectroscopy (CeMOS), Mannheim University of Applied Sciences, Paul-Wittsack-Str. 10, D68163 Mannheim, Germany; m.raedle@hs-mannheim.de

$5 \mathrm{MD}, \mathrm{PhD}$ in Medicine, Professor for Anesthesiology and Intensive Care Medicine, Head of Hygiene Department, University Medical Center Mannheim, Theodor-Kutzer-Ufer 1-3, D-68167 Mannheim, Germany; alexandra.heininger@umm.de

* Correspondence: elmar.bourdon@medtech.uni-heidelberg.de; Tel.: +49 15254693258

\begin{abstract}
Physical distancing and wearing a face mask are key interventions to prevent COVID-19. While this remains difficult to practice for millions of firefighters in fire engines responding to emergencies, the delayed forthcoming of evidence on the physical effectiveness of such safety interventions in this setting presents a major problem. In this field experimental study, we provided initial evidence to close this gap. We examined total aerosol burden in the cabin of a fire engine whilst manipulating crew size, natural ventilation, use of FFP2 respirators and use of SCBA full-face masks during 15-minute driving periods. At the same time, we controlled for crew activity and speaking, vehicle speed, cabin air temperature, pressure and humidity. Limiting the crew size, using FFP2 respirators and not donning SCBA full-face masks was associated with a reduction of the arithmetic mean of total aerosol burden of up to $49 \%$. Natural ventilation as tested in this study was associated with both an increase and a decrease of total aerosol burden. This study provided initial evidence on the physical effectiveness of safety interventions in fire engines to reduce potential airborne transmission of SARS-CoV-2 through aerosols. More research about the physical and clinical effectiveness of such safety interventions is needed.
\end{abstract}

Keywords: SARS-CoV-2; COVID-19; Safety Interventions; Fire Engine; Vehicle, Aerosol; Fine Dust Measurement

\section{Introduction}

In 2018 the international association of fire and rescue services reported more than 14 million firefighters responding to almost 48 million calls in countries worldwide, thereof three million fires. A large majority of these fire services were provided by volunteer firefighters [1]. During the same period in Germany 22,155 volunteer community fire departments, 104 paid municipal fire departments and 771 factory fire departments responded to $4,488,680$ calls, thereof 248,077 fires [2]. It is considered essential to maintain 
these critical infrastructures during the current coronavirus disease 2019 (COVID-19) pandemic with more than 115 million confirmed COVID-19 cases and more than 2.5 million deaths reported worldwide by March 2021 [3].

COVID-19 is caused by the severe acute respiratory syndrome coronavirus 2 (SARS$\mathrm{CoV}-2$ ). Current evidence suggests that this virus spreads in small liquid particles from an infected person's mouth or nose when they cough, sneeze, speak or breathe heavily. These small liquid particles range from liquid aerosols (size $<5 \mu \mathrm{m}$ ) up to respiratory droplets (size $>5 \mu \mathrm{m}$ ). While bigger droplets fall to the ground quickly, small liquid aerosols can remain in the air for a long time and spread throughout a room. Transmission to other persons occurs when these small liquid particles get inhaled by a susceptive person or via contact with the mucous membrane in the eye or respiratory tract. This is more likely to happen when other persons are in close proximity to an infected person $[4,5]$.

Since December 2020, new coronavirus variants B.1.1.7, B.1.351 and P.1 are rapidly emerging [6]. Latest epidemiological data suggest that these variants are associated with an increase in both transmissibility and mortality [7]. Consequently, physical distancing and wearing a face mask are key safety interventions to prevent SARS-CoV-2 infections among the general public.

However, these interventions remain difficult to practice in fire engines responding to emergency calls. The vehicle cabin equals a tight indoor situation with approximately $8.57 \mathrm{~m}^{3}$ air volume or less. In Germany, the minimum tactical crew size of a standard fire engine LF 20 is 6 persons while its standard tactical crew size is 9 persons [8], resulting in approximately $1.34 \mathrm{~m}^{3}$ and $0.87 \mathrm{~m}^{3}$ air volume in the cabin per person respectively. The distance between crew members in the cabin is one meter and less. When approaching an incident, the crew is usually seated in the cabin for up to 15 minutes. This situation is defined as a high-risk exposure [9]. In case of false alerting or cancellation during approach the crew's period in the cabin may exceed 15 minutes. Critical weather, outside noise interfering with required radio terminal communication or with tactical communication inside and other environmental conditions may limit or prevent the airing of the cabin through open windows.

Moreover, already donning the full-face inhalation mask of the self-contained breathing apparatus (SCBA) in the cabin while the fire engine is approaching presents a widely accepted standard to gain life-saving time. To maximize available air supply in smoke the SCBA's full-face inhalation mask is not connected to the high-pressure tank until entering the smoky area at the incident site. Consequently, these firefighters using SCBA continue breathing unfiltered cabin air and, thus, remain with no respiratory protection against SARS-CoV-2 during approach.

This presents a challenge for volunteer fire departments. The large majority cannot operate with permanent teams or duty schedules. Instead, redundant alerting is used to guarantee for required staffing. Consequently, individuals forming a fire engine crew upon alert vary depending on their actual availability and arrival time at the fire station. Hence, the formation of a permanent crew to limit the spread of this virus is not an option.

Against this background, a variety of COVID-19 safety interventions is practiced in fire engines responding to emergencies. These practices include the reduction of tactical crew size, the use of filtering face piece type FFP2 or surgical masks, the off-label use of fire-resistant full-face-coverings when pulling them over mouth and nose, and the use of mechanical or natural ventilation as is felt appropriate or feasible.

To date there has been no data available on the physical effectiveness of those safety interventions in this specific setting, neither for a single COVID-19 safety intervention nor 
for a combination of different interventions. With millions of firefighters worldwide being in this high-risk exposure situation on every call, and their limited access to vaccination at present, this lack of evidence is considered a major issue.

Therefore, we collected original data in a field experiment on March 21st, 2021 using a novel ProxiCube ${ }^{\circledR}$ NX 3 detector device in a pre-production ProxiCube-p design (Nevoox Europe GmbH, Mannheim, Germany) to investigate associations between combinations of COVID-19 safety interventions and total aerosol burden in a German standard fire engine LF 20 responding to a mock fire emergency. Our aim was to provide initial evidence and to immediately translate it into initial guidance for decision making at the frontline of emergency response practice.

\section{Materials and Methods}

Nine study participants were recruited through March 2021 and met the following criteria: completed basic training for fire service and SCBA use, fit for duty, no facial hair, active member of a German fire department, successful SARS-CoV-2 vaccination and no active SARS-CoV-2 infection. The vaccination success was determined by an antibody assay against the spike protein (Elecsys Anti-SARS-CoV-2-S, Roche diagnostics, Mannheim, Germany) according to the manufacturer-specific cut off. Exclusion of an active SARSCoV-2 infection was achieved by molecular genetic analysis of a combined nasopharyngeal swab using an IVD-labeled automated assay (Cepheid, Xpert® Xpress SARS-CoV-2, Sunvalley, CA, U.S.).

The study was conducted in accordance with the Declaration of Helsinki and approved under the project identification code 2021-535-AF5 by the research ethics committee of the Medical Faculty Mannheim of Heidelberg University. All subjects gave their informed consent for inclusion before they participated in the study and all contributing fire departments approved participation of the subjects.

We used a German standard fire engine type LF 20 built to German standard DIN 14530-11, manufactured in December 2014 by Albert Ziegler GmbH, Germany on a Mercedes-Benz 1529 Atego 4×2/4160 chassis. The cabin included a total of nine seats, with two seats in the front and seven seats in the back area of the cabin. There was no wall or window separating the front area from the back area. Air volume of the cabin with nine persons seated was approximately $7.81 \mathrm{~m}^{3}$, thereof approximately $3.55 \mathrm{~m}^{3}$ in the front area and approximately $4.26 \mathrm{~m}^{3}$ in the back area. With just six persons seated in the cabin, approximate air volumes were $8.06 \mathrm{~m}^{3}, 3.55 \mathrm{~m}^{3}$ and $4.51 \mathrm{~m}^{3}$ respectively. Due to fragmented interior fitting and varying anatomy of study participants we were not able to determine the air volume of the cabin exactly. The vehicle did not include an air-conditioning system. We switched mechanical ventilation of the cabin to $50 \%$ power. Air outlet was switched to instrument panel/windscreen and air supply was switched to fresh air from outside. The vehicle heating system was switched to the middle temperature setting.

Figure 1 presents the seating in the cabin according to German fire service regulation FwDV3 [8]. The backrest of seats 3, 5, 7 and 8 included an SCBA pack for immediate donning during approach as shown in Figure 2. The distance between individuals seated next to each other was less than one meter in every direction. 


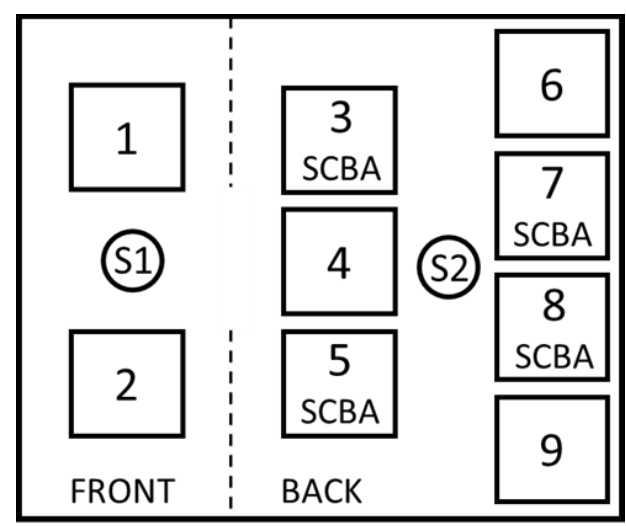

Figure 1. Seating of a standard tactical crew in LF 20 cabin and ProxiCube® positions S1, S2.

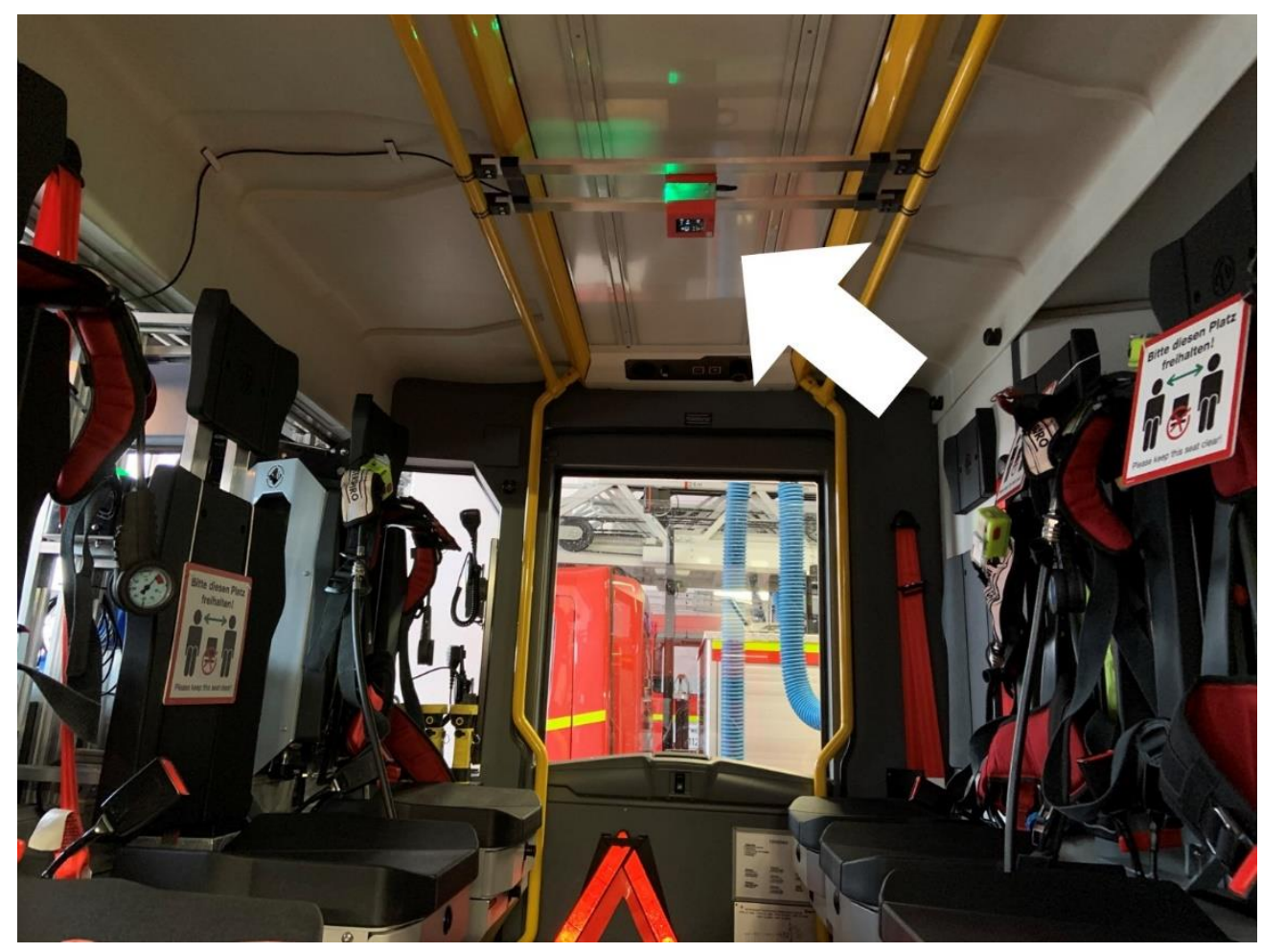

Figure 2. ProxiCube® in back area position S2 (white arrow).

In order to measure explanatory and control variables, we used two ProxiCube ${ }^{\circledR} \mathrm{NX}$ 3 detector devices (Nevoox Europe $\mathrm{GmbH}$, Mannheim, Germany) in a pre-production ProxiCube-p design as shown in Figure 3. External dimensions of each device were $8 \times 8 \times 8$ $\mathrm{cm}$ and both devices were supplied from the fire engine's electrical system using a $12 \mathrm{~V}$ USB-charging adapter. The devices were mounted at positions S1 and S2 in the fire engine's cabin as indicated in Figures 1, 2 and 3. The vertical distance of S1 and S2 to the ceiling was $75 \mathrm{~cm}$ and $10 \mathrm{~cm}$ respectively. 


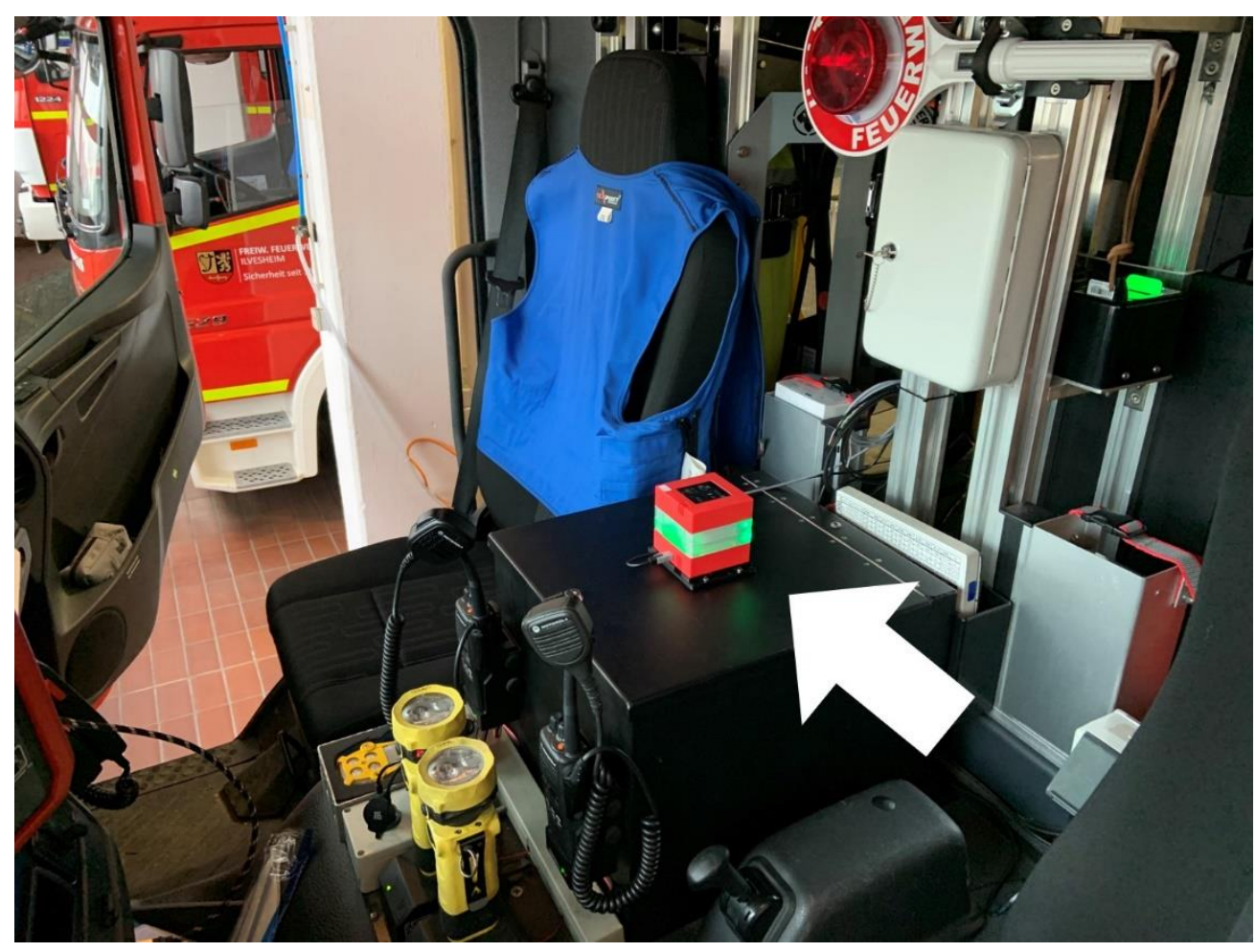

Figure 3. ProxiCube ${ }^{\circledR}$ in front area position $\mathrm{S} 1$ (white arrow).

Particle measurement was based on single particle detection by light extinction. All dispersive events, i.e. both solid particles and liquid particles, were measured together. Each particle and droplet were measured and subsequently classified into the four size channels $<1 \mu \mathrm{m}, 1$ to $<2.5 \mu \mathrm{m}, 2,5$ to $<4 \mu \mathrm{m}$ and 4 to $10 \mu \mathrm{m}$. Particles or droplets that were larger than $10.0 \mu \mathrm{m}$ were not classified. Every aerosol value presented in this study is at any one time the sum of these four size channels. On March 1st, 2021 we validated the ProxiCube ${ }^{\circledR}$ NX 3 devices in the pre-production ProxiCube-p design for use in this study by performing reference laboratory measurements with the Fidas ${ }^{\circledR} 200$ high-precision aerosol measurement system (Palas $\mathrm{GmbH}$, Karlsruhe, Germany).

In all experimental cases, every study participant wore a basic set of personal protective equipment according to German accident prevention regulation UVV Feuerwehren [10] including fire helmet, firefighter turnout gear and safety boots. We used commercially available particle filtering half masks ZN9501 FFP2 NR (Anhui Zhongnan Air Defense Works Co. Ltd., China) according to European standard EN 149:2001+A1:2009 and CEcertified by CCQS Certification Services Ltd., Dublin, Ireland (Notified Body 2834).

The mobile COVID-19 test unit CoVLAB was used for SARS-CoV-2 diagnostics prior to experiment. CoVLAB is a 40-ton truck including an S2-safety laboratory with highthroughput molecular diagnostics technology, offering approximately 60 minutes from PCR- and Antibody-sampling to result [11].

Notations and descriptions of variables are included in Table 1 below. The leftmost column presents the abbreviation for these variables used later in the text. An " $\mathrm{X}$ " signifies that the tabulated values were recorded or applied in the respective experimental setup. An empty box signifies that the condition described was not monitored or applied in that experimental setup. 
Table 1. Notations and descriptions of variables, and experimental setup in cases investigated.

\begin{tabular}{|c|c|c|c|c|c|c|c|c|c|c|c|c|c|}
\hline \multirow{2}{*}{\multicolumn{2}{|c|}{$\begin{array}{l}\text { Notations and descriptions of variables } \\
\text { Dependent variables }\end{array}$}} & \multicolumn{12}{|c|}{ Experimental setup in cases investigated } \\
\hline & & 1 & 2 & 3 & 4 & 5 & 6 & 7 & 8 & 9 & 10 & 11 & 12 \\
\hline AS1_05 & Arithm. mean of total aerosol in $\mu \mathrm{g} / \mathrm{m}^{3}$ at $\mathrm{S} 1$ during $1-5 \mathrm{~min}$ & $\mathrm{X}$ & $\mathrm{x}$ & $\mathrm{x}$ & $\mathrm{X}$ & $\mathrm{X}$ & $\mathrm{X}$ & $\mathrm{X}$ & $\mathrm{x}$ & $\mathrm{x}$ & $\mathrm{X}$ & $\mathrm{X}$ & $\mathrm{X}$ \\
\hline AS1_10 & Arithm. mean of total aerosol in $\mu \mathrm{g} / \mathrm{m}^{3}$ at $\mathrm{S} 1$ during $1-10 \mathrm{~min}$ & $\mathrm{X}$ & $\mathrm{x}$ & $\mathrm{X}$ & $\mathrm{x}$ & $\mathrm{x}$ & $\mathrm{X}$ & $\mathrm{X}$ & $\mathrm{x}$ & $\mathrm{X}$ & $\mathrm{X}$ & $\mathrm{X}$ & $\mathrm{X}$ \\
\hline AS1_15 & Arithm. mean of total aerosol in $\mu \mathrm{g} / \mathrm{m}^{3}$ at $\mathrm{S} 1$ during $1-15 \mathrm{~min}$ & $\mathrm{x}$ & $\mathrm{X}$ & $\mathrm{X}$ & $\mathrm{x}$ & $\mathrm{x}$ & $\mathrm{x}$ & $\mathrm{x}$ & $\mathrm{x}$ & $\mathrm{x}$ & $\mathrm{X}$ & $\mathrm{x}$ & $\mathrm{X}$ \\
\hline AS2_05 & Arithm. mean of total aerosol in $\mu \mathrm{g} / \mathrm{m}^{3}$ at $\mathrm{S} 2$ during $1-5 \mathrm{~min}$ & $\mathrm{x}$ & $\mathrm{x}$ & $\mathrm{X}$ & $\mathrm{X}$ & $\mathrm{x}$ & $\mathrm{x}$ & $\mathrm{x}$ & $\mathrm{x}$ & $\mathrm{x}$ & $\mathrm{X}$ & $\mathrm{X}$ & $\mathrm{X}$ \\
\hline AS2_10 & Arithm. mean of total aerosol in $\mu \mathrm{g} / \mathrm{m}^{3}$ at $\mathrm{S} 2$ during $1-10 \mathrm{~min}$ & $\mathrm{x}$ & $\mathrm{x}$ & $\mathrm{X}$ & $\mathrm{x}$ & $\mathrm{x}$ & $\mathrm{x}$ & $\mathrm{x}$ & $\mathrm{x}$ & $\mathrm{x}$ & $\mathrm{x}$ & $\mathrm{x}$ & $\mathrm{X}$ \\
\hline AS2_15 & Arithm. mean of total aerosol in $\mu \mathrm{g} / \mathrm{m}^{3}$ at $\mathrm{S} 2$ during $1-15 \mathrm{~min}$ & $\mathrm{x}$ & $\mathrm{X}$ & $\mathrm{x}$ & $\mathrm{x}$ & $\mathrm{x}$ & $\mathrm{X}$ & $\mathrm{x}$ & $\mathrm{X}$ & $\mathrm{X}$ & $\mathrm{X}$ & $\mathrm{x}$ & $\mathrm{X}$ \\
\hline \multicolumn{14}{|c|}{ Explanatory variables (COVID-19 safety interventions) } \\
\hline CS9 & Standard tactical crew size on seats 1 to 9 & $\mathrm{X}$ & $\mathrm{X}$ & $\mathrm{x}$ & $\mathrm{x}$ & $\mathrm{X}$ & $\mathrm{X}$ & & & & & & \\
\hline CS6 & Reduced tactical crew size on seats $1-3,5,7$ and 8 only & & & & & & & $\mathrm{x}$ & $\mathrm{x}$ & $\mathrm{x}$ & $\mathrm{x}$ & $\mathrm{x}$ & $\mathrm{X}$ \\
\hline WIC & No natural ventilation with windows closed & $\mathrm{X}$ & $\mathrm{X}$ & $\mathrm{X}$ & & & & $\mathrm{x}$ & $\mathrm{x}$ & $x$ & & & \\
\hline WIO & Moderate natural ventilation with windows partially opened $10 \mathrm{~cm}$ & & & & $\mathrm{x}$ & $\mathrm{X}$ & $\mathrm{X}$ & & & & $\mathrm{x}$ & $\mathrm{x}$ & $\mathrm{x}$ \\
\hline NOR & No respiratory protection of crew in cabin & $\mathrm{X}$ & & & $\mathrm{x}$ & & & $\mathrm{X}$ & & & $\mathrm{x}$ & & \\
\hline REP & Respiratory protection of crew in cabin using FFP2 respirators & & $\mathrm{X}$ & $\mathrm{X}$ & & $\mathrm{X}$ & $\mathrm{X}$ & & $\mathrm{x}$ & $\mathrm{x}$ & & $\mathrm{X}$ & $\mathrm{x}$ \\
\hline DOF & Donning of SCBA fullface mask in cabin & $\mathrm{X}$ & $\mathrm{X}$ & & $\mathrm{X}$ & $\mathrm{X}$ & & $\mathrm{x}$ & $x$ & & $\mathrm{x}$ & $\mathrm{X}$ & \\
\hline NOF & Not donning on of SCBA fullface mask in cabin & & & $x$ & & & $X$ & & & $x$ & & & $\mathrm{X}$ \\
\hline \multicolumn{14}{|c|}{ Control variables } \\
\hline VES & Vehicle speed $35 \mathrm{~km} / \mathrm{h}$ & $\mathrm{X}$ & $\mathrm{X}$ & $X$ & $\mathrm{X}$ & $\mathrm{X}$ & $X$ & $\mathrm{X}$ & $\mathrm{x}$ & $\mathrm{X}$ & $x$ & $\mathrm{X}$ & $\mathrm{X}$ \\
\hline STA & Standardized activity of crew in cabin according to script & $\mathrm{x}$ & $\mathrm{x}$ & $\mathrm{x}$ & $\mathrm{x}$ & $\mathrm{x}$ & $\mathrm{x}$ & $\mathrm{x}$ & $\mathrm{x}$ & $\mathrm{x}$ & $\mathrm{x}$ & $\mathrm{X}$ & $\mathrm{X}$ \\
\hline STS & Standardized speaking of crew in cabin according to script & $\mathrm{x}$ & $\mathrm{X}$ & $\mathrm{x}$ & $\mathrm{X}$ & $\mathrm{x}$ & $\mathrm{x}$ & $\mathrm{x}$ & $\mathrm{x}$ & $\mathrm{x}$ & $\mathrm{x}$ & $\mathrm{X}$ & $\mathrm{X}$ \\
\hline MIT1 & Minimum temperature ${ }^{\circ} \mathrm{C}$ at $\mathrm{S} 1$ & $\mathrm{x}$ & $x$ & $\mathrm{x}$ & $\mathrm{x}$ & $\mathrm{x}$ & $\mathrm{x}$ & $\mathrm{x}$ & $\mathrm{x}$ & $\mathrm{x}$ & $x$ & $\mathrm{x}$ & $\mathrm{X}$ \\
\hline MAT1 & Maximum temperature ${ }^{\circ} \mathrm{C}$ at $\mathrm{S} 1$ & $\mathrm{x}$ & $\mathrm{x}$ & $\mathrm{x}$ & $\mathrm{x}$ & $\mathrm{x}$ & $\mathrm{x}$ & $\mathrm{x}$ & $x$ & $\mathrm{x}$ & $x$ & $\mathrm{x}$ & $x$ \\
\hline $\mathrm{MIH} 1$ & Minimum absolute humidity in $\mathrm{g} / \mathrm{m}^{3}$ at $\mathrm{S} 1$ & $\mathrm{X}$ & $\mathrm{x}$ & $\mathrm{x}$ & $\mathrm{x}$ & $\mathrm{x}$ & $\mathrm{x}$ & $x$ & $\mathrm{x}$ & $\mathrm{x}$ & $x$ & $\mathrm{x}$ & $\mathrm{x}$ \\
\hline MAH1 & Maximum absolute humidity in $\mathrm{g} / \mathrm{m}^{3}$ at $\mathrm{S} 1$ & $\mathrm{x}$ & $\mathrm{x}$ & $x$ & $\mathrm{x}$ & $\mathrm{x}$ & $\mathrm{x}$ & $\mathrm{x}$ & $\mathrm{x}$ & $\mathrm{x}$ & $\mathrm{x}$ & $\mathrm{x}$ & $\mathrm{X}$ \\
\hline MIP1 & Minimum air pressure in mbar at $\mathrm{S} 1$ & $x$ & $x$ & $\mathrm{x}$ & $\mathrm{x}$ & $\mathrm{x}$ & $\mathrm{x}$ & $\mathrm{x}$ & $x$ & $x$ & $x$ & $\mathrm{x}$ & $\mathrm{x}$ \\
\hline MAP1 & Maximum air pressure in mbar at $\mathrm{S} 1$ & $x$ & $x$ & $\mathrm{x}$ & $\mathrm{x}$ & $\mathrm{x}$ & $\mathrm{x}$ & $\mathrm{x}$ & $x$ & $x$ & $x$ & $\mathrm{x}$ & $\mathrm{x}$ \\
\hline MIT2 & Minimum temperature ${ }^{\circ} \mathrm{C}$ at $\mathrm{S} 2$ & $\mathrm{x}$ & $x$ & $\mathrm{x}$ & $\mathrm{x}$ & $\mathrm{x}$ & $\mathrm{x}$ & $\mathrm{x}$ & $\mathrm{x}$ & $\mathrm{x}$ & $\mathrm{x}$ & $\mathrm{x}$ & $\mathrm{x}$ \\
\hline MAT2 & Maximum temperature ${ }^{\circ} \mathrm{C}$ at $\mathrm{S} 2$ & $\mathrm{X}$ & $\mathrm{X}$ & $\mathrm{x}$ & $\mathrm{x}$ & $\mathrm{x}$ & $\mathrm{x}$ & $\mathrm{x}$ & $\mathrm{x}$ & $\mathrm{x}$ & $\mathrm{x}$ & $\mathrm{x}$ & $\mathrm{X}$ \\
\hline $\mathrm{MIH} 2$ & Minimum absolute humidity in $\mathrm{g} / \mathrm{m}^{3}$ at $\mathrm{S} 2$ & $\mathrm{x}$ & $x$ & $x$ & $\mathrm{x}$ & $\mathrm{x}$ & $x$ & $\mathrm{x}$ & $\mathrm{x}$ & $\mathrm{x}$ & $\mathrm{x}$ & $\mathrm{x}$ & $\mathrm{X}$ \\
\hline $\mathrm{MAH} 2$ & Maximum absolute humidity in $\mathrm{g} / \mathrm{m}^{3}$ at $\mathrm{S} 2$ & $\mathrm{x}$ & $x$ & $\mathrm{x}$ & $\mathrm{x}$ & $\mathrm{x}$ & $\mathrm{x}$ & $x$ & $x$ & $\mathrm{x}$ & $x$ & $\mathrm{x}$ & $x$ \\
\hline MIP2 & Minimum air pressure in mbar at S2 & $\mathrm{x}$ & $\mathrm{X}$ & $\mathrm{x}$ & $\mathrm{x}$ & $\mathrm{x}$ & $\mathrm{x}$ & $\mathrm{x}$ & $\mathrm{x}$ & $\mathrm{x}$ & $x$ & $\mathrm{x}$ & $\mathrm{X}$ \\
\hline MAP2 & Maximum air pressure in mbar at $\mathrm{S} 2$ & $\mathrm{x}$ & $x$ & $\mathrm{x}$ & $x$ & $x$ & $\mathrm{x}$ & $x$ & $x$ & $\mathrm{x}$ & $x$ & $x$ & $x$ \\
\hline
\end{tabular}

Against the background of today's German fire service system and geographical allocation of fire stations, a five-minute driving period is considered to occur in a majority of emergency calls. Upon alert, German fire service performance guidelines for fighting fires in residential buildings require the first standard fire engine to arrive at the incident site after no longer than ten minutes and the second standard fire engine to arrive after no longer than 15 minutes [12]. Therefore, we investigated dependent, explanatory and control variables in three intervals: during the first five minutes, during the first ten minutes, and during the entire 15 minutes of each experimental case.

Total aerosol burden in $\mu \mathrm{g} / \mathrm{m}^{3}$ measured at front area position S1 and total aerosol burden measured at back area position S2 represented the dependent variables of the study

Explanatory variables included a standard tactical crew size of nine persons, a reduced tactical crew size of six persons, no natural ventilation with windows closed, moderate natural ventilation with all four cabin windows opened $10 \mathrm{~cm}$, no respiratory protection of crew in cabin and respiratory protection of crew in cabin using FFP2 respirators, donning and not donning of a disconnected SCBA full-face mask on seats 3, 5, 7 and 8 respectively.

Control variables were vehicle speed of $35 \mathrm{~km} / \mathrm{h}$, crew activity in the cabin standardized as donning a fire hood and the SCBA high-pressure tank, and gathering a handheld 
radio terminal, a hand lamp and a thermal camera on seats 3, 5, 7 and 8 with crew members on seats 4, 6 and 9 assisting them according to a standardized scripted procedure, and also speaking in cabin standardized using a script. Scripts are included in Appendix A and B for experimental cases with 9 and 6 persons respectively. Prior to these experiments, activity and speaking scripts were trained by the crew, and the fire engine's captain monitored full compliance to scripts on board. Additional control variables included air temperature in cabin in ${ }^{\circ} \mathrm{C}$, air pressure in cabin in mbar and absolute humidity in cabin in $\mathrm{g} / \mathrm{m}^{3}$ as measured with the two ProxiCube-p pre-production devices in positions $\mathrm{S} 1$ and $\mathrm{S} 2$ respectively.

Experimental cases were performed on Sunday, March 21st, 2021 between 10:56h and 17:01h (UTC+1) in 68549 Ilvesheim, Germany, on a standardized driving route on public streets. Weather conditions during the experimental period were observed as follows: cloudy, temperature between 5.4 and $9.6 C^{\circ}$, relative humidity between 55 and $67 \%$, and moderate to no wind from south-west. During experimental case 2, we encountered light rain or drizzle.

Table 1 shows the twelve experimental cases under study. In every case we investigated a different combination of COVID-19 safety interventions. Case 1 is considered a reference case with applying no explanatory COVID-19 safety interventions while case 12 represents a potential maximum safety case applying all COVID-19 safety interventions tested in this study.

Before the start of the first experimental case, every study participant underwent a swab for PCR testing and a blood draw for antibody testing.

After the health test results were available, we assigned seat positions 1 (driver) and 2 (captain) to two study participants with the required qualification and randomized the remainder of study participants to seat positions 3 to 9 . This initial assignment of participants to seat positions 1 to 9 remained constant throughout the study.

Prior to the start of every experimental case the four doors of the empty cabin were kept fully open for 10 minutes outside the fire station. In cases 4 to 6 and 10 to 12 , windows were opened $10 \mathrm{~cm}$ before the start of the experiment.

After proceeding to assigned cabin seats in a fire drill manner, we closed the cabin doors, immediately accelerated the fire engine to $35 \mathrm{~km} /$ and kept this speed until the end of experiment. Each experimental period ranged from 00:00 minutes (closing of doors) to 15:02 minutes. In cases 1 to 12 the COVID-19 safety interventions under study were applied as indicated in Table 1.

After completion of every 15-minute experimental period the fire engine was stopped in front of the fire station, SCBA full-face masks were taken off again, SCBA high-pressure tanks and all other equipment were made ready for use again, and study participants left the cabin. Thereafter all cabin doors were kept fully open again for 10 minutes.

In experimental cases with FFP2 respirator use, these were put on just prior to proceeding to cabin seats and proper fit was tested according to instructions for use. Three FFP2 respirators were marked with both a personalized code and a consecutive number and were provided to each study participant for rolling exchange between experimental cases. Thus, an FFP2 respirator used for 15 minutes in a previous experimental case was hung up in the fire station to dry and air for 60 minutes before being used again.

We measured total aerosol burden, cabin air temperature, absolute humidity and cabin air pressure every 11 seconds at S1 and S2 from start to end of each 15-minute ex- 
perimental case. Thus, we produced 83 data points for each of these eight variables respectively. Data were acquired using the two validated ProxiCube ${ }^{\circledR}$ NX 3 devices in the ProxiCube-p pre-production design.

In experimental cases 1, 2, 4, 5, 7, 8, 10 and 11 participants on seat positions 3, 5, 7 and 8 took off their FFP2 mask and subsequently put on a fire-resistant hood, a high-pressure tank, an SCBA full-face mask and other equipment. The SCBA full-face mask was not connected to the SCBA high-pressure tank. Consequently, they continued breathing cabin air without any respiratory protection. In cases 3, 6, 9 and 12 these participants did not put on the SCBA full-face mask but continued using their FFP2 mask instead.

Data were transmitted in real-time from the two ProxiCube-p devices to a central data repository (Pfalzkom Datacenter, Mutterstadt, Germany) using WLAN and LTE technology. Subsequently data were analyzed using Microsoft Excel 2019 (Microsoft Corporation, USA).

\section{Results}

Tables 2 and 3 provide a comparative overview of experimental cases in the front area position S1 and in back area position S2. Tables include real-time (UTC+1), arithmetic mean values of total aerosol burden in $\mu \mathrm{g} / \mathrm{m}^{3}$ during the first 5 minutes, during the first 10 minutes and during the entire 15 minutes of experimental cases. We also indicated the change within each experimental case from AS1_05 to AS1_15 and from AS2_05 to AS2_15 in percent. Moreover, minimum and maximum values of control variables are included.

Figures 4 to 6 and 7 to 9 present a comparative boxplot overview of total aerosol burden in $\mu \mathrm{g} / \mathrm{m}^{3}$ during the first 5 minutes, during the first 10 minutes and during the entire 15 minutes of experimental cases as measured at front area position S1 and back area position S2. The box includes the middle $50 \%$ of all data points. The lower end of the box marks the first $25 \%$ of data points (first quartile). The upper end of the box marks the first $75 \%$ of data points (third quartile) and the median is marked in between. The cross in each box indicates the arithmetic mean of data points (83 in 15 min period) measured for each case. Potential maximum length of whiskers equals 1.5 times of the interquartile range. Points above or below whiskers mark statistical outliers. The red dotted line marks the arithmetic mean of total aerosol as measured for reference case 1 with no COVID-19 safety intervention. 
3.1 Total aerosol burden measured at front area sensor position S1

Table 2. Results for total aerosol burden and control variables at front area position S1.

\begin{tabular}{|c|c|c|c|c|c|c|c|c|c|c|c|c|}
\hline \multirow{2}{*}{$\begin{array}{l}\text { S1 front } \\
\text { Dependent }\end{array}$} & \multicolumn{12}{|c|}{ Experimental cases } \\
\hline & 1 & 2 & 3 & 4 & 5 & 6 & 7 & 8 & 9 & 10 & 11 & 12 \\
\hline Start time & $10: 56: 03$ & 11:51:14 & 13:33:21 & $14: 27: 04$ & $15: 20: 58$ & $16: 20: 00$ & $11: 23: 55$ & $13: 05: 51$ & $13: 59: 56$ & $14: 54: 23$ & $15: 48: 39$ & $16: 46: 46$ \\
\hline End time & 11:11:05 & $12: 06: 16$ & $13: 48: 23$ & $14: 42: 06$ & $15: 36: 00$ & $16: 35: 02$ & $11: 38: 57$ & $13: 20: 53$ & $14: 14: 58$ & $15: 09: 25$ & 16:03:41 & 17:01:48 \\
\hline AS1_05 & 108.5 & \begin{tabular}{|l|}
82.1 \\
\end{tabular} & \begin{tabular}{|l|}
55.3 \\
\end{tabular} & \begin{tabular}{|l|}
95.1 \\
\end{tabular} & \begin{tabular}{|l|}
67.8 \\
\end{tabular} & \begin{tabular}{|l|}
58.2 \\
\end{tabular} & \begin{tabular}{|l|}
88.4 \\
\end{tabular} & \begin{tabular}{|l|}
70.2 \\
\end{tabular} & \begin{tabular}{|l|}
74.7 \\
\end{tabular} & 96.2 & 90.8 & \begin{tabular}{|l|}
69.8 \\
\end{tabular} \\
\hline AS1_10 & 98.4 & 75.1 & 60.4 & 98.0 & 73.6 & 63.1 & 80.3 & 69.3 & 70.5 & 84.6 & 84.1 & 71.7 \\
\hline AS1_15 & 91.9 & 74.8 & 61.8 & 98.7 & 75.1 & 69.4 & 75.3 & 67.3 & 70.2 & 82.1 & 80.6 & 72.6 \\
\hline Change \% & -15.3 & -9.0 & 11.8 & 3.8 & 10.7 & 19.2 & -14.8 & -4.1 & -6.0 & -14.7 & -11.2 & 4.1 \\
\hline \multicolumn{13}{|l|}{ Explanatory } \\
\hline CS9 & $\mathrm{x}$ & $\mathrm{x}$ & $\mathrm{x}$ & $\mathrm{x}$ & $\mathrm{x}$ & $\mathrm{x}$ & & & & & & \\
\hline CS6 & & & & & & & $x$ & $x$ & $x$ & $x$ & $x$ & $x$ \\
\hline WIC & $x$ & $x$ & $x$ & & & & $x$ & $x$ & $x$ & & & \\
\hline WIO & & & & $\mathrm{x}$ & $\mathrm{x}$ & $\mathrm{x}$ & & & & $\mathrm{x}$ & $\mathrm{x}$ & $\mathrm{x}$ \\
\hline NOR & $x$ & & & $x$ & & & $x$ & & & $x$ & & \\
\hline REP & & $x$ & $x$ & & $\mathrm{x}$ & $\mathrm{x}$ & & $\mathrm{x}$ & $\mathrm{x}$ & & $\mathrm{x}$ & $\mathrm{x}$ \\
\hline DOF & $x$ & $x$ & & $x$ & $x$ & & $x$ & $x$ & & $x$ & $x$ & \\
\hline NOF & & & $x$ & & & $\mathrm{x}$ & & & $\mathrm{x}$ & & & $\mathrm{x}$ \\
\hline \multicolumn{13}{|l|}{ Control } \\
\hline MIT1 & 17.2 & 22.5 & 21.4 & 22.1 & 23.7 & 20.4 & 19.8 & 24.0 & 22.6 & 21.8 & 22.6 & 20.1 \\
\hline MAT1 & 23.2 & 27.9 & 27.4 & 23.2 & 24.6 & 21.9 & 25.6 & 28.7 & 28.2 & 23.5 & 23.1 & 21.3 \\
\hline $\mathrm{MIH} 1$ & 16.7 & 14.6 & 17.5 & 16.3 & 14.2 & 15.6 & 15.8 & 15.8 & 16.3 & 15.0 & 15.0 & 16.3 \\
\hline MAH1 & 20.8 & 18.0 & 21.6 & 18.7 & 15.6 & 18.1 & 19.5 & 18.8 & 19.6 & 18.2 & 17.3 & 18.5 \\
\hline MIP1 & 1002 & 1002 & 1001 & 1000 & 999 & 999 & 1002 & 1001 & 1000 & 999 & 999 & 999 \\
\hline MAP1 & 1003 & 1002 & 1002 & 1001 & 1000 & 1000 & 1002 & 1002 & 1001 & 1000 & 1000 & 1000 \\
\hline
\end{tabular}

As revealed in Table 2 and Figures 4 to 6 for S1, during the first 5 minutes the largest decrease of the arithmetic mean of total aerosol compared to reference case 1 with 108.5 $\mu \mathrm{m} / \mathrm{m}^{3}$ was recognized in case 3 with $55.3 \mu \mathrm{m} / \mathrm{m}^{3}$. This equals a reduction of -49 percent. During the first 10 and during the entire 15 minutes, the largest reduction was also detected in case 3 . These reductions equaled -39 and -33 percent respectively.

The second largest decrease versus reference case 1 was discovered for case 6 with a reduction of -46 and -36 percent during the first 5 and the first 10 minutes respectively. During the first 15 minutes, cases 6 and 8 produced comparable reductions of -25 and -27 percent respectively, when compared to reference case 1 .

The smallest decrease against reference case 1 was reported for case 4 with a reduction of -12 and 0 percent during the first 5 and the first 10 minutes. During the first 15 minutes we observed even an increase of the arithmetic mean of total aerosol of +7 percent verses reference case 1.

When looking at changes between AS1_05 and AS1_15 in each of the experimental cases in Table 2, these changes ranged from a decrease of -15.3 in case 1 to an increase of 19.2 percent in case 6 .

We observed cabin air temperatures from 17.2 in case 1 up to 28.7 degrees Celsius in case 8 , and absolute humidity was seen from 14.2 in case 5 up to 21.6 grams per cubic meter in case 3 . The minimum of cabin air pressure was 999 in five cases and the maximum was 1003 millibar in case 1. 
Total Aerosol Burden measured from minute 1 to 5 at S1

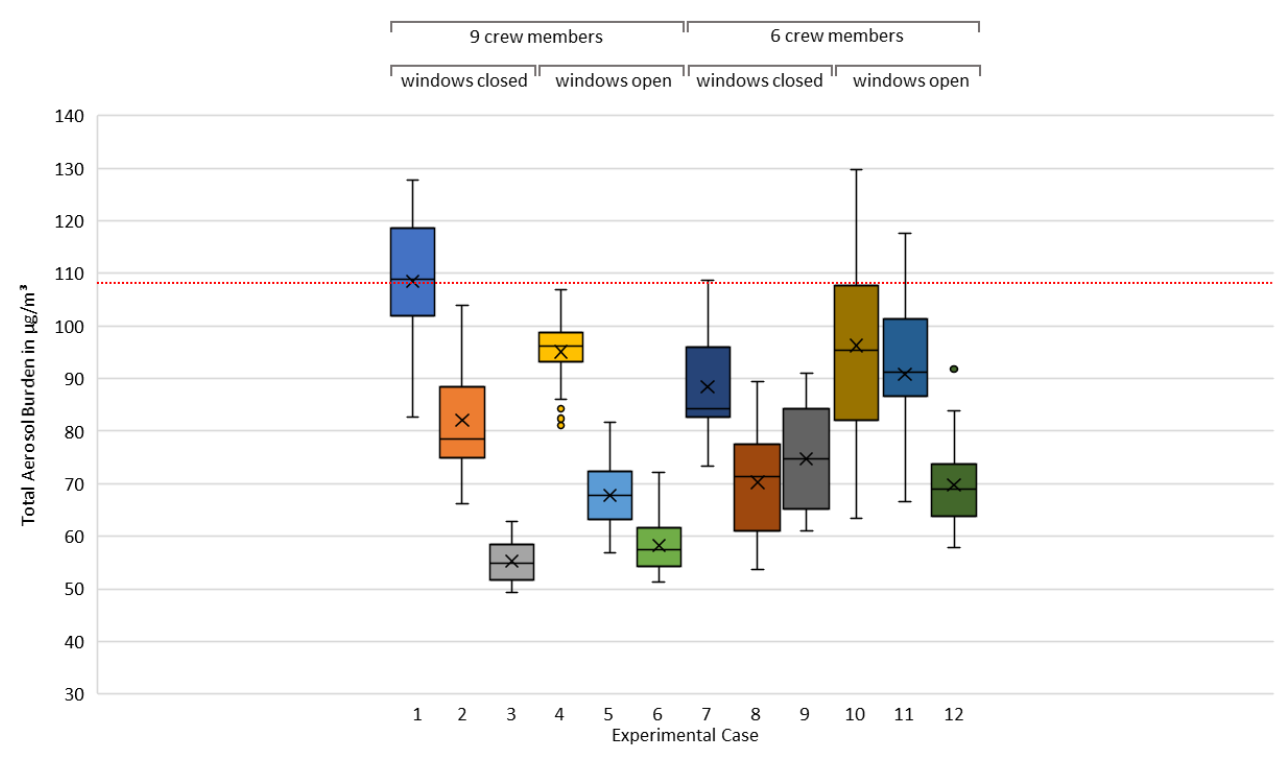

Figure 4. Total aerosol burden measured from minute 1 to 5 at front area position S1.

Total Aerosol Burden measured from minute 1 to 10 at S1

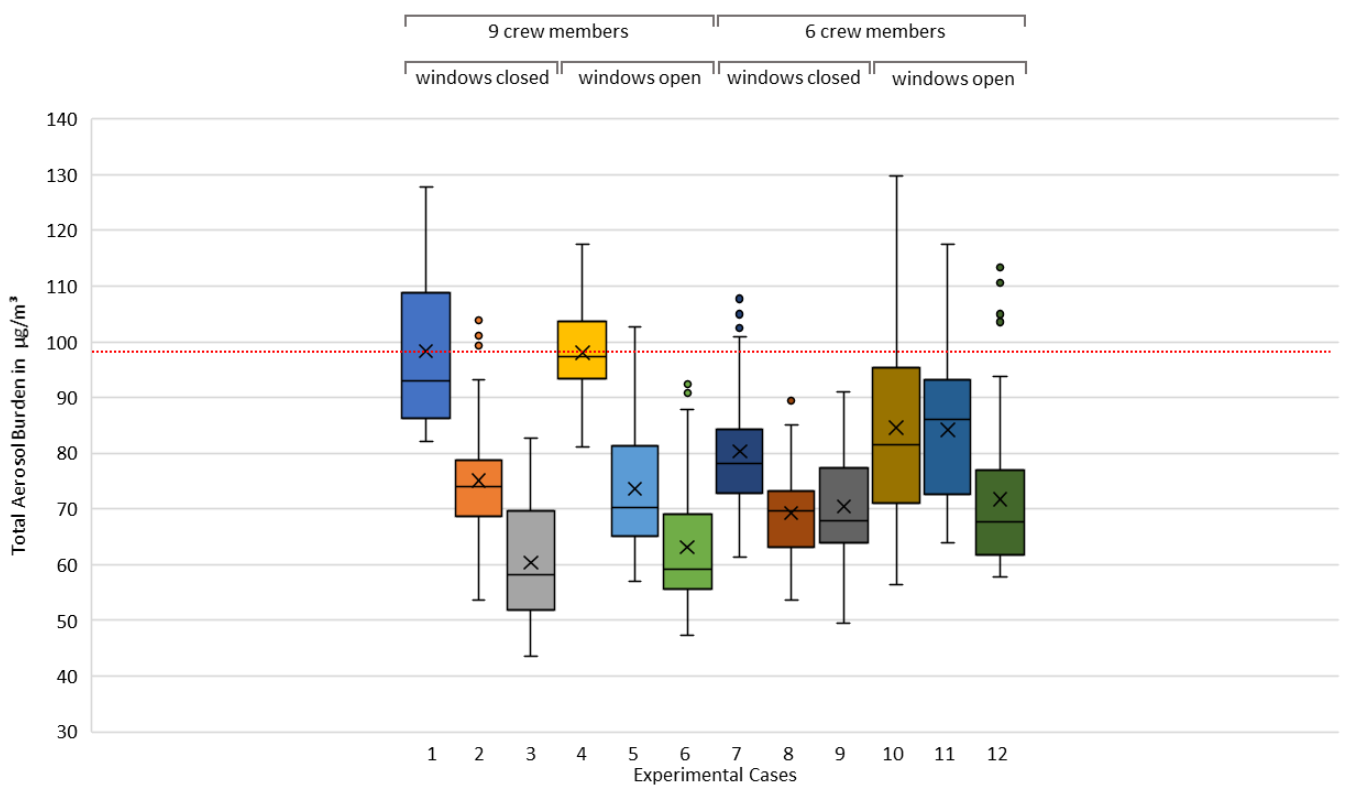

Figure 5. Total aerosol burden measured from minute 1 to 10 at front area position S1. 
Total Aerosol Burden measured from minute 1 to 15 at S1

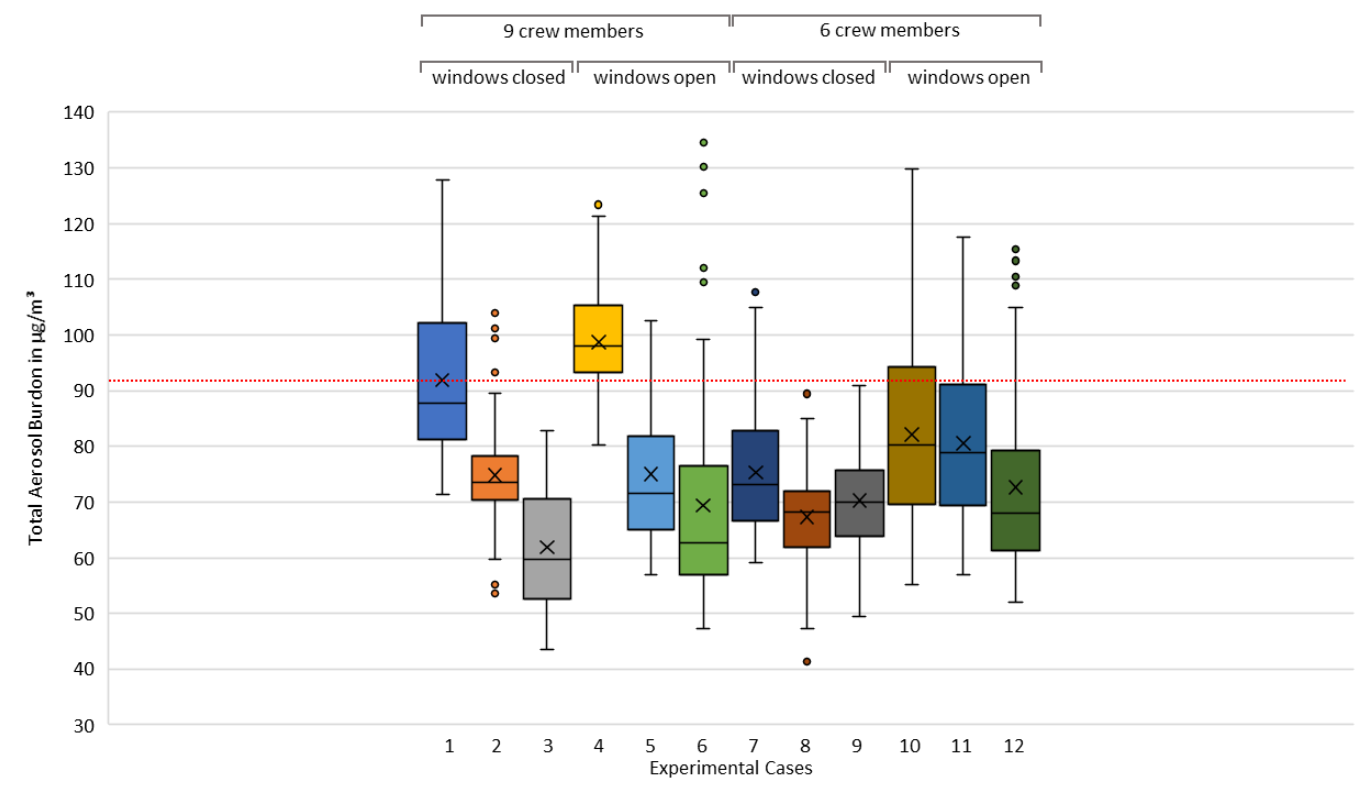

Figure 6. Total aerosol burden measured from minute 1 to 15 at front area position S1.

3.2 Total aerosol burden measured at back area sensor position S2

Table 3. Results for total aerosol burden and control variables at back area position S2.

\begin{tabular}{|c|c|c|c|c|c|c|c|c|c|c|c|c|}
\hline \multirow{2}{*}{$\begin{array}{l}\text { S2 back } \\
\text { Dependent }\end{array}$} & \multicolumn{12}{|c|}{ Experimental cases } \\
\hline & 1 & 2 & 3 & 4 & 5 & 6 & 7 & 8 & 9 & 10 & 11 & 12 \\
\hline Start time & $10: 56: 03$ & 11:51:14 & 13:33:21 & $14: 27: 04$ & 15:20:58 & 16:20:00 & 11:23:55 & 13:05:51 & 13:59:56 & $14: 54: 23$ & $15: 48: 39$ & $16: 46: 46$ \\
\hline End time & $11: 11: 05$ & $12: 06: 16$ & $13: 48: 23$ & $14: 42: 06$ & $15: 36: 00$ & $16: 35: 02$ & $11: 38: 57$ & $13: 20: 53$ & $14: 14: 58$ & $15: 09: 25$ & $16: 03: 41$ & $17: 01: 48$ \\
\hline AS2_05 & \begin{tabular}{|l|l}
98.8 \\
\end{tabular} & \begin{tabular}{|l|}
73.6 \\
\end{tabular} & \begin{tabular}{|l|}
50.7 \\
\end{tabular} & \begin{tabular}{|l|}
91.1 \\
\end{tabular} & \begin{tabular}{|l|}
70.1 \\
\end{tabular} & 56.3 & 82.4 & \begin{tabular}{|l|}
63.9 \\
\end{tabular} & \begin{tabular}{|l|}
66.2 \\
\end{tabular} & \begin{tabular}{|l|}
97.3 \\
\end{tabular} & \begin{tabular}{|l|}
90.3 \\
\end{tabular} & \begin{tabular}{|l|}
71.8 \\
\end{tabular} \\
\hline AS2_10 & 87.8 & 71.5 & 56.7 & 97.7 & 73.4 & 62.0 & 73.7 & 66.1 & 65.2 & 82.4 & 87.2 & 72.7 \\
\hline AS2_15 & 83.3 & 72.0 & 58.4 & 99.1 & 76.5 & 69.1 & 71.2 & 64.7 & 65.6 & 82.6 & 82.3 & 73.6 \\
\hline Change \% & -15.7 & -2.2 & 15.3 & 8.8 & 9.2 & 22.6 & -13.5 & 1.1 & -0.9 & -15.1 & -8.9 & 2.4 \\
\hline \multicolumn{13}{|l|}{ Explanatory } \\
\hline CS9 & $\mathrm{x}$ & $\mathrm{X}$ & $x$ & $x$ & $x$ & $\mathrm{X}$ & & & & & & \\
\hline CS6 & & & & & & & $x$ & $x$ & $x$ & $x$ & $x$ & $x$ \\
\hline WIC & $x$ & $x$ & $x$ & & & & $x$ & $x$ & $x$ & & & \\
\hline WIO & & & & $x$ & $x$ & $x$ & & & & $x$ & $\mathrm{x}$ & $\mathrm{x}$ \\
\hline NOR & $x$ & & & $x$ & & & $x$ & & & $x$ & & \\
\hline REP & & $x$ & $\mathrm{x}$ & & $x$ & $x$ & & $x$ & $x$ & & $\mathrm{x}$ & $x$ \\
\hline DOF & $x$ & $x$ & & $x$ & $x$ & & $x$ & $x$ & & $x$ & $x$ & \\
\hline NOF & & & $x$ & & & $x$ & & & $x$ & & & $x$ \\
\hline \multicolumn{13}{|l|}{ Control } \\
\hline MIT2 & 20.0 & 25.6 & 24.4 & 22.7 & 22.1 & 20.8 & 24.1 & 26.6 & 26.0 & 22.2 & 21.2 & 20.4 \\
\hline MAT2 & 24.8 & 29.6 & 29.3 & 25.2 & 22.8 & 21.7 & 27.8 & 29.8 & 30.2 & 22.8 & 22.4 & 21.5 \\
\hline $\mathrm{MIH} 2$ & 14.6 & 12.3 & 14.6 & 13.4 & 14.6 & 14.1 & 11.9 & 13.5 & 13.4 & 14.9 & 15.5 & 15.2 \\
\hline MAH2 & 19.9 & 15.6 & \begin{tabular}{l|l}
19.3 \\
\end{tabular} & 16.2 & \begin{tabular}{ll|}
16.4 \\
\end{tabular} & 16.7 & 15.8 & 16.5 & 16.1 & 17.0 & 17.3 & 17.0 \\
\hline MIP2 & 1001 & 1001 & 1000 & 999 & 999 & 999 & 1001 & 1001 & 1000 & 999 & 999 & 999 \\
\hline MAP2 & 1002 & 1002 & 1001 & 1000 & 1000 & 1000 & 1002 & 1001 & 1001 & 1000 & 1000 & 1000 \\
\hline
\end{tabular}

As shown in Table 3 and Figures 7 to 9 for S2, during the first 5 minutes the largest decrease of the arithmetic mean of total aerosol compared to reference case 1 with 98.8 $\mu \mathrm{m} / \mathrm{m}^{3}$ was recognized in case 3 with $50.7 \mu \mathrm{m} / \mathrm{m}^{3}$. This equals a reduction of -49 percent. During the first 10 and during the entire 15 minutes the largest reduction was also detected in case 3 . Reductions equaled -35 and -30 percent respectively.

The second largest decrease versus reference case 1 was recorded for case 6 with a reduction of -43 and -29 percent during the first five and the first 10 minutes respectively. 
During the first 15 minutes, cases 6,8 and 9 produced comparable reductions of $-17,-22$ and -21 percent respectively, when compared to reference case 1 .

The smallest decrease against reference case 1 was reported for case 10 during the first 5 minutes with a reduction of -2 percent. During the first 10 and during the entire 15 minutes this changed and we observed for case 4 even an increase of the arithmetic mean of total aerosol of +11 and +19 percent versus reference case 1 .

When analyzing changes between AS2_05 and AS2_15 in each of the experimental cases of Table 3, these changes ranged from a decrease of -15.7 in case 1 to an increase of 22.6 percent in case 6 .

Furthermore, we observed cabin air temperatures from 20.0 in case 1 to 30.2 degrees Celsius in case 9, and absolute humidity was seen from 11.9 in case 7 to 19.9 grams per cubic meter in case 1 . The minimum of cabin air pressure was 999 in six cases and the maximum was 1002 millibar in three cases, as displayed in Table 3.

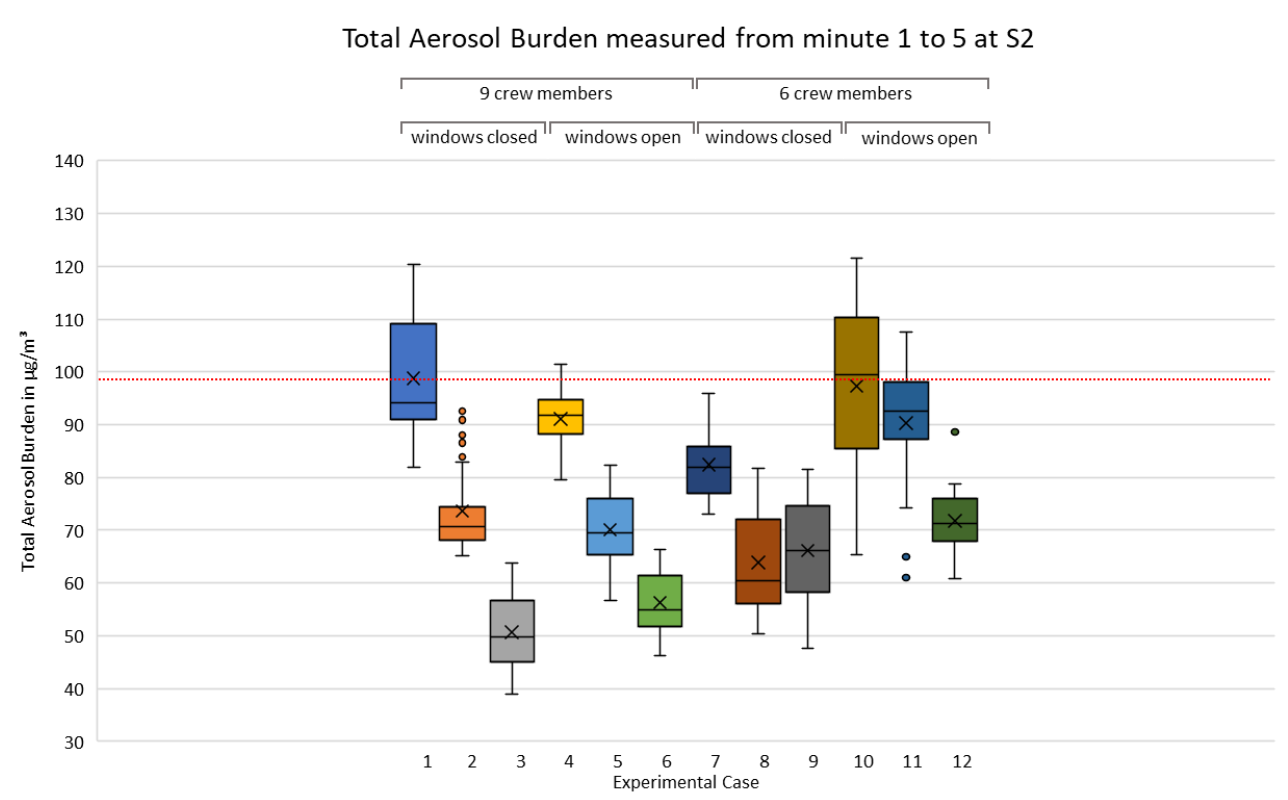

Figure 7. Total aerosol burden measured from minute 1 to 5 at back area position S2. 
Total Aerosol Burden measured from minute 1 to 10 at S2

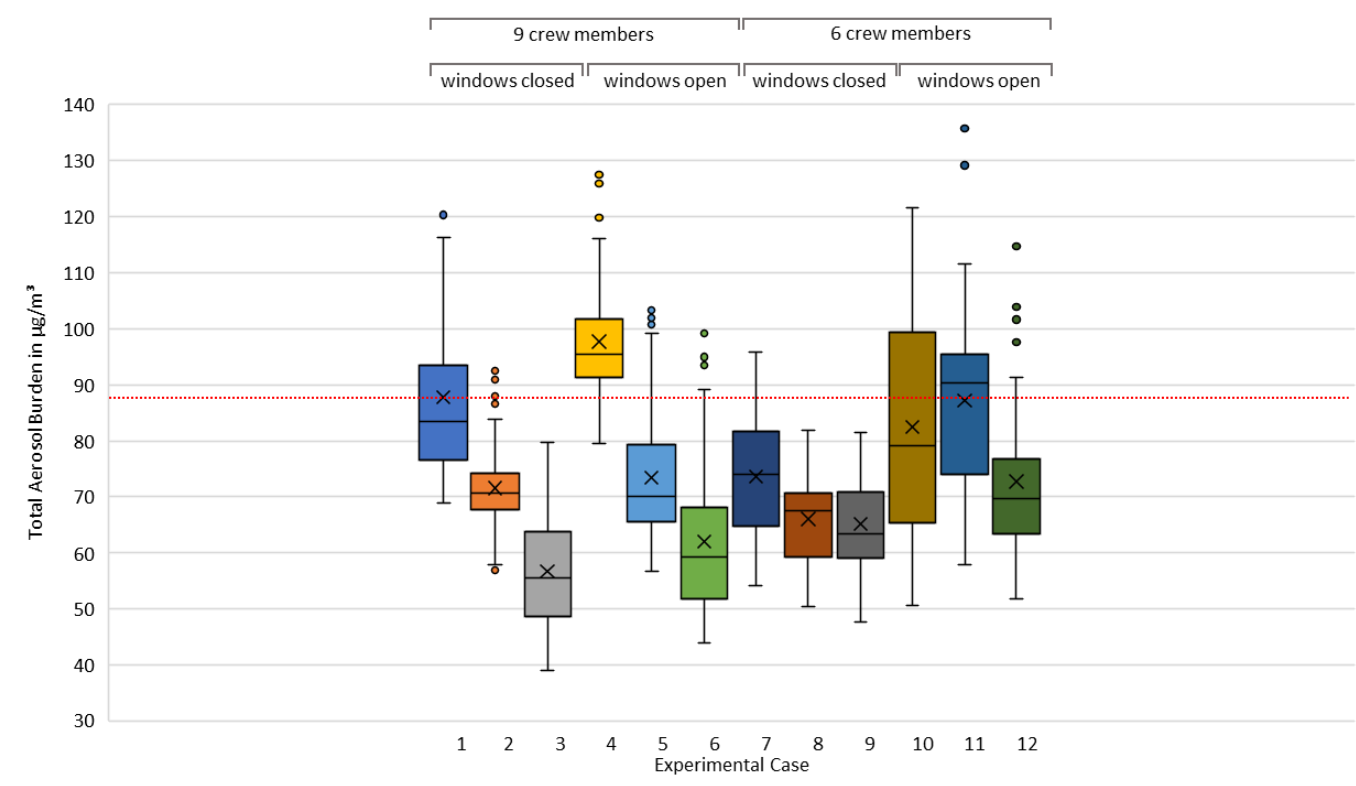

Figure 8. Total aerosol burden measured from minute 1 to 10 at back area position S2.

Total Aerosol Burden measured from minute 1 to 15 at S2

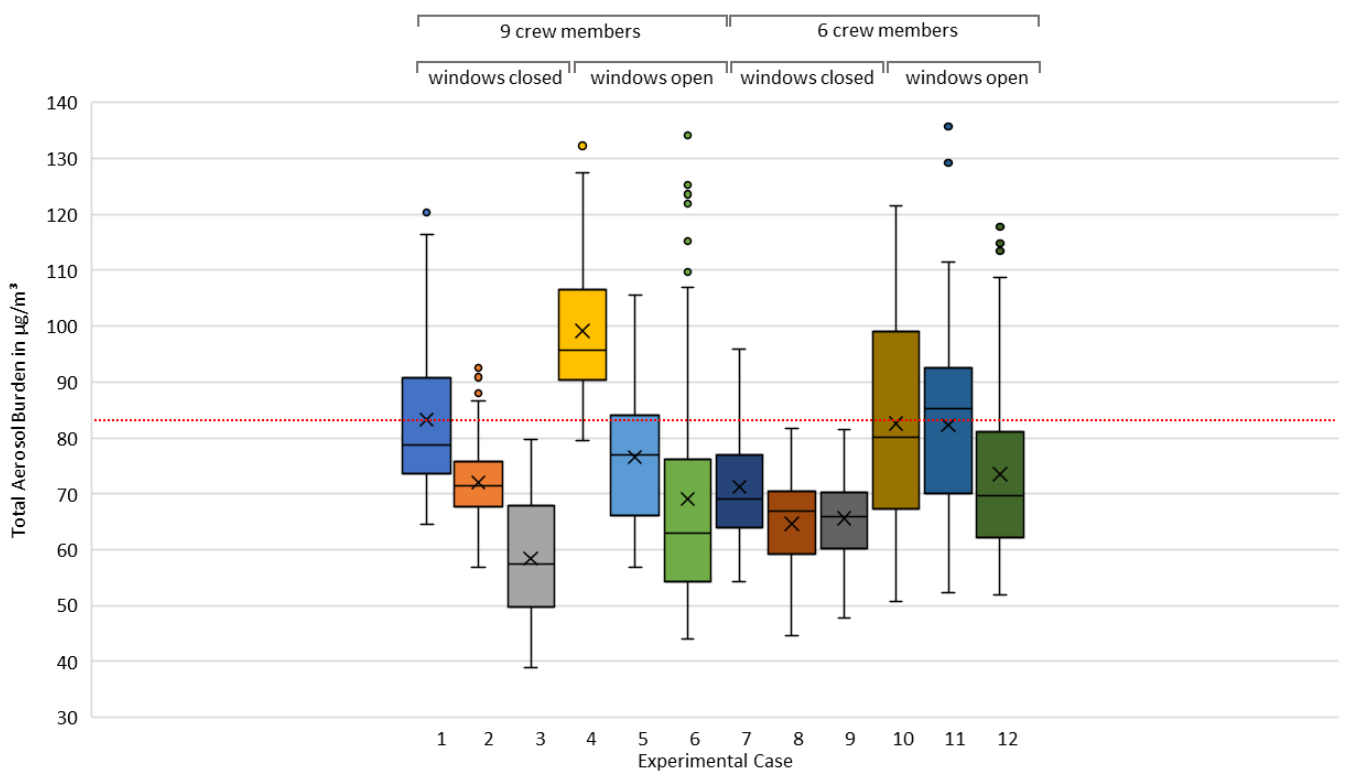

Figure 9. Total aerosol burden measured from minute 1 to 15 at back area position S2. 


\subsection{Observations related to both sensor positions S1 and S2}

The captain of the fire engine reported minor changes of environmental conditions and minor events non-compliant to the study protocol as presented in Table 4.

Table 4. Changes of environmental conditions and events non-compliant to the study protocol.

\begin{tabular}{|c|c|c|c|c|c|}
\hline \multirow{2}{*}{ Case } & \multirow{2}{*}{$\begin{array}{c}\text { Start time of } \\
\text { experiment }\end{array}$} & \multicolumn{2}{|c|}{ Event observed } & \multirow{2}{*}{ Description of event } & \multirow{2}{*}{$\begin{array}{l}\text { End time of } \\
\text { experiment }\end{array}$} \\
\hline & & from & to & & \\
\hline 1 & 10:56:03 & - & - & no event reported & 11:11:05 \\
\hline \multirow{2}{*}{2} & 11:51:14 & $11: 51: 26$ & $11: 51: 30$ & stop of fire engine at stop sign or traffic light for $4 \mathrm{sec}$ & 12:06:16 \\
\hline & 11:51:14 & $11: 51: 14$ & $12: 06: 16$ & light rain or drizzle during entire 15:02 experimental period & 12:06:16 \\
\hline 3 & $13: 33: 21$ & $13: 35: 52$ & $13: 35: 56$ & stop of fire engine at stop sign or traffic light for $4 \mathrm{sec}$ & $13: 48: 23$ \\
\hline 4 & 14:27:04 & $14: 27: 24$ & $14: 27: 29$ & stop of fire engine at stop sign or traffic light for $5 \mathrm{sec}$ & $14: 42: 06$ \\
\hline \multirow{3}{*}{5} & $15: 20: 58$ & $15: 21: 15$ & $15: 21: 20$ & stop of fire engine at stop sign or traffic light for $5 \mathrm{sec}$ & $15: 36: 00$ \\
\hline & $15: 20: 58$ & $15: 22: 52$ & $15: 22: 54$ & stop of fire engine at stop sign or traffic light for $2 \mathrm{sec}$ & $15: 36: 00$ \\
\hline & $15: 20: 58$ & $15: 35: 49$ & $15: 36: 00$ & stop of fire engine at stop sign or traffic light for $11 \mathrm{sec}$ & $15: 36: 00$ \\
\hline 6 & $16: 20: 00$ & - & - & no event reported & $16: 35: 02$ \\
\hline 7 & 11:23:55 & $11: 26: 13$ & $11: 26: 24$ & stop of fire engine at stop sign or traffic light for $11 \mathrm{sec}$ & $11: 38: 57$ \\
\hline 8 & 13:05:51 & - & - & no event reported & $13: 20: 53$ \\
\hline 9 & 13:59:56 & 14:02:09 & 14:02:19 & stop of fire engine at stop sign or traffic light for $10 \mathrm{sec}$ & $14: 14: 58$ \\
\hline 10 & $14: 54: 23$ & 14:56:39 & 14:56:43 & stop of fire engine at stop sign or traffic light for $5 \mathrm{sec}$ & 15:09:25 \\
\hline \multirow{2}{*}{11} & 15:48:39 & 15:49:39 & 15:50:39 & spurious alarm of SCBA deadman warning device on seat 8 for $1 \mathrm{~min}$ & 16:03:41 \\
\hline & 15:48:39 & $15: 50: 29$ & 15:50:34 & stop of fire engine at stop sign or traffic light for $5 \mathrm{sec}$ & 16:03:41 \\
\hline 12 & $16: 46: 46$ & $16: 47: 04$ & $16: 47: 12$ & stop of fire engine at stop sign or traffic light for $8 \mathrm{sec}$ & $17: 01: 48$ \\
\hline
\end{tabular}

\section{Discussion}

We used two independent sensors of the same type at the same time at different positions in the middle plane of the cabin, albeit at different heights within the cabin. Therefore, we considered our collected raw data to be robust. However, our dynamic field experiment may have included a variety of human, technical and environmental variables of potential influence that we were not able to manipulate or to control for. Consequently, a spread of data was expected and seen in each experimental case.

Our investigation included twelve experimental cases, with each case comprising a different combination of COVID-19 safety interventions as was described in Table 1 above. Case 1 represented a reference case while applying none of the safety interventions under study. Each of the further cases 2 to 12 included a different combination of safety interventions. In case 12, we applied all safety interventions of the study.

From a general perspective, when compared to case 1, all other cases were associated with a lower arithmetic mean of total aerosol, except for cases 3, 10 and 12 at certain time periods.

Figures 4 to 9 revealed that cases 1, 2 and 3 (blue, orange, light grey) form a cascade pattern, i.e. a single safety intervention applied was associated with a substantial decrease of aerosol burden, while applying an additional safety intervention, all other things equal, was associated with an additional substantial decrease of aerosol burden. We found the same to apply to cases 4,5 and 6 (yellow, light blue, green).

More specifically, we noticed in Figures 4 to 9 that the lowest total aerosol burden was associated with case 3 (light grey). Case 3 comprised the use of FFP2 respirators and not donning SCBA full-face masks, while nine crew members were on board and windows were closed. We consider this result remarkable, as we initially expected case 12 to be associated with the lowest aerosol burden. 
As can be derived from case 3 in Tables 2 and 3, the single effect size of FFP2 use seems to approximately equal the single effect size of not donning SCBA full-face masks, resulting in a combined total effect size of -49 percent at position S1 and -49 percent at position S2. This appears conclusive, since in case 3 the four SCBA users out of the nine crew members did not breath unfiltered cabin air but continued wearing FFP2 respirators, like all other crew members did.

As previously mentioned, donning SCBA full-face masks in the cabin, but keeping them disconnected from the SCBA high-pressure tank during response, is seen as a common practice to gain life-saving time. In light of our initial evidence, practitioners may reconsider the risks and benefits of common SCBA practice and review alternative practice standards for emergency calls with required SCBA use.

As can be recognized in Figures 4 to 9, the second lowest arithmetic mean of total aerosol was recognized for case 6 (green) with using FFP2 respirators and not donning SCBA full-face masks, nine crew members on board, but with windows $10 \mathrm{~cm}$ open. This was observed both during the first 5 minutes and during the first 10 minutes. When analyzing the entire 15-minute period, we discovered a similar total aerosol burden in case 6 (green) and in case 8 (brown), the latter with a reduced crew size of 6 persons. When compared to case 8 (brown) we saw a slightly higher arithmetic mean value und a slightly lower median value for case 6 (green) at S1 and S2.

As described, case 1 represented a reference case of our study protocol, with applying none of the safety interventions under study. As can be seen in Tables 2 and 3, and in Figures 4 to 9, we confirmed this for the arithmetic mean of total aerosol during the first five minutes both at front area position S1 and the back area position S2.

In contrast, during the first 10 and during the entire 15-minute interval we noticed case 4 to represent the worst case with, all other things equal to case 1, windows $10 \mathrm{~cm}$ open. This was unexpected, as we considered windows $10 \mathrm{~cm}$ open a safety intervention that potentially reduces aerosol burden.

At this point, our findings suggest that combinations of safety interventions as applied in case 3 might provide the lowest aerosol burden in the cabin. If not applicable in a specific emergency response situation, e.g. due to organizational restrictions or critical environmental conditions outside, then a combination of safety interventions as applied either in case 6 (green) or in case 8 (brown) might be considered as an alternative option.

Tables 2 and 3 as well as Figures 4 to 9 reveal more specific detail on the physical effectiveness of reducing crew size and opening windows $10 \mathrm{~cm}$. When compared to corresponding cases with standard crew size, the reduction of crew size to six persons appeared to create adverse effects with increasing aerosol burden. Similar apparently adverse effects were realized for opening windows $10 \mathrm{~cm}$ when compared to corresponding cases with windows closed.

More specifically, associations of a reduced tactical crew size of six persons and a decrease of total aerosol burden were detected in Figures 4 to 9 for cases 7 and 8 (dark blue and brown) when compared to their corresponding cases 1 and 2 (blue and orange). This suggests that a reduction of crew size from nine to six persons might be physically effective to reduce potential transmission of SARS-CoV-2 when windows are closed. This appears to be generally conclusive, since a reduction of crew size creates more cabin air volume and, in principle, leads to less emission of aerosol.

However, when juxtaposing cases 5 and 6 (light blue and green) with windows 10 $\mathrm{cm}$ open to their corresponding cases 11 and 12 (dark blue, dark green) with windows 10 
$\mathrm{cm}$ open we found reverse effects of reducing crew size, i.e. an increase of total aerosol at positions S1 and S2. Consequently, while windows are open as tested in this study, a reduction of tactical crew size might yet be associated with an increase of aerosol burden. More research is required to investigate this reverse phenomenon.

Moreover, the physical effectiveness of reducing crew size seemed also to be reversed through the additional not donning of SCBA full-face masks, as can be seen in corresponding cases 3 (grey) and 9 (dark grey). In principle, not donning SCBA full-face masks leads to less crew activity and to less aerosol emission as the four crew members on seats 3, 5, 7 and 8 are less active, and continue using their FFP2 masks instead of breathing unfiltered air through disconnected SCBA full-face masks. Therefore, we found this observation inconclusive. Further research is needed to investigate this specific issue.

In cases 4, 5 and 6 (yellow, light blue and green) at front area position S1, we saw that windows $10 \mathrm{~cm}$ open created a decrease and at the same time also an increase of total aerosol when compared to cases 1, 2 and 3 (blue, orange and light grey) with windows closed. This applied to all of the three experimental periods. When performing the same analysis for back area position S2, we saw this during the 5 five-minute period, too. For the first 10 minutes and for the entire 15-miniute period, we observed opening of windows $10 \mathrm{~cm}$ to increase total aerosol values.

This latter finding may partially result from an influx of outside fine dust while driving on a public urban street at $35 \mathrm{~km} / \mathrm{h}$ speed. Moreover, working in firefighting and technical emergency environments leads to fine dust settling onto surfaces of the interior installation and equipment in the cabin, and onto the firefighter's turnout gear. Elevated air flow through open windows might have raised this fine dust from those surfaces into the cabin air.

Yet, the role of natural ventilation as investigated in this study remains unclear. Further research on the characteristics of airflow and on the spatial distribution of aerosols in our specific setting is needed, and we recommend a differentiated measurement of solid and liquid aerosols in future studies.

Tables 2 and 3 revealed how the arithmetic mean of total aerosol changed in each case when comparing the first 5 minutes to the entire 15-minute experimental period. In the front area position S1 these changes ranged from -15.3 to 19.2 percent and in the back area position S2 from -15.7 to 22.6 percent. Cases 1, 2, 7 and 9 to 12 present a decrease, while cases 3 to 6 and 12 show an increase. In case 8 we noticed little to no change. The direction and the size of these changes do not appear to correspond substantially to any of our explanatory or control variables, and, thus might be subject to other human, technical and environmental variables of potential influence.

However, when looking at longitudinal raw data of the cases investigated, aerosol burden appeared to plateau in each case, yet this plateau differed subject to the variables applied in each experimental case. This plateau might result from a continuous air flow through the fire engine cabin created by the mechanical ventilation, which was set to $50 \%$ power, fresh air inlet and to instrument panel/windshield outlet. Consequently, our finding supports the use of these specific ventilation settings in a fire engine.

Air pressure in the cabin ranged from 999 to $1003 \mathrm{mbar}$, air temperature in cabin ranged from 17.2 to $30.2^{\circ} \mathrm{C}$ and absolute humidity in cabin ranged from 11.9 to $21.6 \mathrm{~g} / \mathrm{m}^{3}$ across all experimental cases. When comparing values of total aerosol burden to values of these three control variables on a case-by-case basis, the variances of these three control variables seemed too small for causal relationships with total aerosol burden as measured. 
Recent evidence suggest that different levels of humidity potentially facilitate the airborne transmission of SARS-CoV-2 through aerosols in indoor situations [13].

When analyzing the environmental changes and non-compliant events reported in Table 4, we considered these changes and events to be negligible. Longitudinal raw data for the experimental period of case 11 demonstrated that the elevated total aerosol burden at S1 and S2 discovered in Figures 4 to 9 were not associated to the non-compliant handling of the SCBA spurious alarm that occurred during the first 5 minutes.

In summary, we found the use of FFP2 respirators and not donning SCBA full-face masks might be physically effective to substantially reduce total aerosol burden if windows are closed, mechanical ventilation is switched to 50 percent power and fresh air outlet is set to instrument panel/windshield.

Our findings may be generalizable to the use of other respirators following performance standards N95 (United States NIOSH-42CFR84), KN95 (China GB2626-2006), P2 (Australia/New Zealand AS/NZA 1716:2012), Korea 1st class (Korea KMOEL - 2017-64), DS2 (Japan JMHLW-Notification 214, 2018) and PFF2 (ABNT/NBR 13.698-2011 - Brazil) [14].

Moreover, we found the reduction of tactical crew size to six persons might be physically effective with or without the use of FFP2 respirators if windows are closed, mechanical ventilation is switched to 50 percent power and fresh air outlet is set to instrument panel/windshield. The physical effectiveness of additionally not donning SCBA full-face masks in this specific setting remained unclear.

We found insufficient evidence to confirm the physical effectiveness of opening windows $10 \mathrm{~cm}$ as a single COVID-19 safety intervention.

Our findings appear to be partially in contrast to current guidelines from fire service authorities, from healthcare authorities and from occupational safety agencies. To date, these bodies generally recommend a reduction of the tactical crew size in fire engines, and at the same time the opening of windows.

\section{Conclusions}

Keeping a minimum distance and using face coverings are considered key interventions to reduce the airborne transmission of coronavirus SARS-CoV-2 through aerosols and thus, to prevent COVID-19. These interventions are difficult to implement for millions of firefighters during an emergency response. Furthermore, a variety of additional COVID-19 safety interventions in such a setting is emerging in firefighting practice, while the delayed forthcoming of evidence on the physical effectiveness of these practices is considered a major problem.

To the best of these authors' collective knowledge, there has been no data available on the association of the safety interventions examined in this study and total aerosol burden in fire engines responding to an emergency call. In this field experimental study, we collected unique new data that supports closing of this gap. Our empirical investigation has established implications for both research and practitioners.

From a research perspective, our data suggests that certain combinations of COVID19 safety interventions in fire engines might be physically effective to reduce the total aerosol burden and, thus, the potential airborne transmission of SARS-CoV-2. 
From a practitioner's perspective, this study is a call to action for reviewing COVID19 safety interventions in fire engines as practiced to date. Results may provide initial guidance for decision makers in firefighting practice, but also in similar organizational and vehicle settings, like e.g. in civil protection services, emergency medical services, police and military services.

Considering the risk associated with future coronavirus variants, future influenza virus variants and to other communicable diseases with similar modes of transmission through airborne particles, this study may also support decision making in occupational medicine beyond SARS-CoV-2.

Although the data of our study can be regarded as a unique first step in establishing rational, fact-based protocols for establishing emergency response procedures, it is nonetheless subject to several limitations. These include, but are not limited to, small dataset size, measurement of total aerosol burden rather than liquid aerosol burden and only 4 potential safety interventions. Making these measurements in an actual emergency setting under reproducible conditions is extremely challenging and sometimes surprising since some obvious candidate safety interventions had either no or no consistent effect reducing total aerosol burden. More research about the physical and clinical effectiveness of these and other COVID-19 safety interventions at the local practice level is urgently needed. 
Author Contributions: Conceptualization, E.B, T.S., M.R. and A.H.; Methodology, E.B.; Software, T.S.; Validation, M.R., T.S.; Formal Analysis, E.B. and M.R.; Investigation, E.B., T.S., M.K., M.R., A.H.; Resources, E.B., T.S., M.K., M.R.; Data Curation, T.S., M.K.; Writing - Original Draft Preparation, E.B.; Writing - Review \& Editing, E.B., M.K., M.R., A.H.; Visualization, E.B.; Supervision, M.R., A.H.; Project Administration, E.B.; Funding Acquisition, None.

Funding: This research received no external funding.

Institutional Review Board Statement: The study was conducted according to the guidelines of the Declaration of Helsinki and approved by the Ethics Committee of Medical Faculty Mannheim of Heidelberg University (project identification code 2021-535-AF).

Informed Consent Statement: Informed consent was obtained from all subjects involved in the study.

Data Availability Statement: Data is contained within the article. Further study data and data on laboratory reference measurements are not publicly available due to privacy or ethical reasons. Depending on a specific request, and subject to both, previous approval in written of coauthors and ethical compliance, it may be made available from the corresponding author.

Acknowledgements: Measuring aerosol burden in a fire service field experiment during a historical SARS-CoV-2 pandemic presented an extraordinary challenge in this empirical investigation. Therefore, we would like to thank the study participants and their volunteer fire departments, ProxiVision $\mathrm{GmbH}$, Bensheim, Germany, Nevoox Europe $\mathrm{GmbH}$, Mannheim, Germany, Medical Faculty Mannheim of Heidelberg University, Mannheim, Germany and the Baden-Wuerttemberg Stiftung $\mathrm{gGmbH}$, Stuttgart, Germany, for their support, and Dr. Robert L. Shoeman, Max-Planck-Institute for Medical Research, Heidelberg, Germany, for comments on the manuscript.

Conflicts of Interest: Authors Thomas Schaefer and Matthias Raedle have been involved as a consultant and expert witness in ProxiVision $\mathrm{GmbH}$ and in Nevoox Europe GmbH. Authors Thomas Schaefer and Matthias Raedle are the inventors of the patent for the ProxiCube ${ }^{\circledR}$ technology. All other authors declare no conflicts of interest. 


\section{Appendix A}

Script for experimental cases 1 to 6 with standard tactical crew size of 9 persons

(Translated from German original script into English for journal publication)

00:00 Entering of fire engine in fire drill manner, with FFP2 respirators already put on in experimental cases where applicable, immediate closing of doors and start.

00:30 Captain: „Sling on SCBA full-face masks!“

Crew on seats 2 to 9: Repeats simultaneously together "Sling on SCBA full-face masks!“

Crew on seats 3, 5, 7 and 8: Remove their helmet, pull on their fire-resistant hood and sling on SCBA full-face mask around their neck.

Crew on seats 6 and 9: Assist crew on seats 3 and 5.

Crew on seat 4: Assists crew on seats 7 and 8 .

01:00 Captain: „Put on SCBA!“

Crew on seats 2 to 9: Repeats simultaneously together "Put on SCBA!“

Crew on seats 3, 5, 7 and 8: Put on their SCBA high-pressure tank and perform quick check.

Crew on seats 6 and 9: Assist crew on seats 3 and 5.

Crew on seat 4: Assists crew on seats 7 and 8 .

03:00 Captain: „Put on SCBA full-face masks and get ready!“

Crew on seats 2 to 9: Repeats simultaneously together „Put on SCBA full-face masks and get ready!"

Crew on seats 3, 5, 7 and 8: Remove FFP2 respirator (where applicable), put on their SBCA full-face mask, pull on their fire-resistant hood, put on helmet, and take up handheld radio terminal, hand lamp and thermal camera.

Crew on seats 6 and 9: Assist crew on seats 3 and 5 .

Crew on seat 4: Assists crew on seats 7 and 8 .

05:30 Captain: Calls up names of SCBA users for entering into SCBA-monitoring dash board.

Crew on seats 3, 5, 7 and 8: Reply with their names.

06:30 Captain: Reads from e-book in moderate volume.

07:45 Captain: Hands over e-book to seat 5 and subsequently announces the experimental time at every full minute for handing over e-book to the next seat.

08:00 Seat 5 reads from e-book in moderate volume and then hands over.

09:00 Seat 4 reads from e-book in moderate volume and then hands over.

10:00 Seat 3 reads from e-book in moderate volume and then hands over.

11:00 Seat 6 reads from e-book in moderate volume and then hands over.

12:00 Seat 7 reads from e-book in moderate volume and then hands over.

13:00 Seat 8 reads from e-book in moderate volume and then hands over.

14:00 Seat 9 reads from e-book in moderate volume and then hands over.

15:00 Captain: „End of reading!“

15:02 End of experiment.

In cases 3 and 6 where SCBA full-face masks were not put on, the crew was instructed accordingly just prior to the start of the experiment. Standardized speaking and activity according to script remained the same, except for putting on SCBA full-face masks. Thus, crew on seats 3, 5, 7 and 8 continued using FFP2 respirators (where applicable). 


\section{Appendix B}

Script for experimental cases 7 to 12 with reduced tactical crew size of 6 persons

(Translated from German original script into English for journal publication)

00:00 Entering of fire engine in fire drill manner, with FFP2 respirators already put on in experimental cases where applicable, immediate closing of doors and start.

00:30 Captain: „Sling on SCBA full-face masks!“

Crew on seats 2, 3, 5, 7 and 8: Repeats simultaneously together „Sling on SCBA full-face masks!"

Crew on seats 3, 5, 7 and 8: Remove their helmet, pull on their fire-resistant hood and sling on SCBA full-face mask around their neck.

01:00 Captain: „Put on SCBA!“

Crew on seats 3, 5, 7 and 8: Repeats simultaneously together „Put on SCBA!“

Crew on seats 3, 5, 7 and 8: Put on their SBCA high-pressure tank and perform quick check.

03:30 Captain: „Put on SCBA full-face masks and get ready!“

Crew on seats 3, 5, 7 and 8: Repeats simultaneously together "Put on SCBA full-face masks and get ready!"

Crew on seats 3, 5, 7 and 8: Remove FFP2 respirator (where applicable), put on their SBCA full-face mask, pull on their fire-resistant hood, put on helmet, and take up handheld radio terminal, hand lamp and thermal camera.

06:30 Captain: Calls up names of SCBA users for entering into SCBA-monitoring dash board.

Crew on seats 3, 5, 7 and 8: Reply with their names.

07:30 Captain: Reads from e-book in moderate volume.

08:45 Captain: Hands over e-book to seat 5 and subsequently announces the experimental time at every full minute for handing over e-book to the next seat.

09:00 Seat 5 reads from e-book in moderate volume and then hands over.

10:00 Seat 3 reads from e-book in moderate volume and then hands over.

11:00 Seat 7 reads from e-book in moderate volume and then hands over.

12:00 Seat 8 reads from e-book in moderate volume and then hands back to Captain.

13:00 Captain reads from e-book in moderate volume.

14:00 Captain: „End of reading - experiment continues!“

15:02 End of experiment.

In cases 9 and 12 where SCBA full-face masks were not put on, the crew was instructed accordingly just prior to start of the experiment. Standardized speaking and activity according to script remained the same, except for putting on SCBA full-face masks. Thus, crew on seats 3, 5, 7 and 8 continued using FFP2 respirators (where applicable). 


\section{References}

1. International Association of Fire and Rescue Services, Center of Fire Statistics, World Fire Statistics. Available online: https://www.ctif.org/sites/default/files/2018-06/CTIF_Report23_World_Fire_Statistics_2018_vs_2_0.pdf (accessed on 10.02.2021)

2. Deutscher Feuerwehrverband, aktuellste statistische Daten, Anzahl der Feuerwehren. Available online: https://www.feuerwehrverband.de/presse/statistik/ (accessed on 11.02.2021)

3. World Health Organisation, WHO Coronavirus (COVID-19) Dashboard. Available online: https://covid19.who.int/ (accessed 14.03.2021)

4. World Health Organisation, Coronavirus disease (COVID-19): How is it transmitted? Available online: https://www.who.int/news-room/q-a-detail/coronavirus-disease-covid-19-how-is-it-transmitted (accessed 14.02.2021)

5. Meselson, M. Letter to the editor, Droplets and Aerosols in the Transmission of SARS-CoV-2. N Engl J Med 2020, 382, page 2063

6. World Health Organisation, Coronavirus disease (COVID-19), Weekly Epidemiological Update - 2 March 2021. Available online: https://www.who.int/publications/m/item/weekly-epidemiological-update---2-march-2021 (accessed 05.03.2021)

7. Centers for disease control and prevention, About Variants of the Virus that Causes COVID-19. Available online: https://www.cdc.gov/coronavirus/2019-ncov/transmission/variant.html (accessed 15.02.2021)

8. Ausschuss Feuerwehrangelegenheiten, Katastrophenschutz und zivile Verteidigung (AFKzV), Feuerwehr-Dienstvorschrift FwDV 3, Einheiten im Lösch- und Hilfeleistungseinsatz, Stand Februar 2008, page 10

9. European Center for Disease Prevention and Control, Technical Report, Public health management of persons having had contact with cases of COVID-19 in the EU, 25.02.2020, page 2

10. Deutsche Gesetzliche Unfallversicherung, DGUV Vorschrift 49, Unfallverhütungsvorschrift Feuerwehren, Juni 2018, page 14

11. CoVLAB Baden-Wuerttemberg: Die mobile Corona-Teststation. Available online: https://www.covlab.de/die-teststrategie/teststation/ (accessed 20.04.2021)

12. Innenministerium Baden-Wuerttemberg, Hinweise zur Leistungsfähigkeit der Feuerwehr, Januar 2008 page 7-8. Available online: https://www.lfs-bw.de/fileadmin/LFS-BW/themen/gesetze_vorschriften/hinweise/dokumente/Hinweise_Leistungsfaehigkeit_Feuerwehr.pdf (accessed 09.02.2021)

13. Ahlawat, A., Wiedensohler, A., Mishra, S. K. An Overview on the Role of Relative Humidity in Airborne Transmission of SARS-CoV-2 in Indoor Environments. Aerosol Air Qual Res, 2020, 20, page 1856-1861

14. 3M, Technical Bulletin, February 2021, Revision 6, page 1. Available online: https://multimedia.3m.com/mws/media/1791500O/comparison-ffp2-kn95-n95-filtering-facepiece-respirator-classes-tb.pdf (accessed 26.02.2021) 